\title{
Conceptual Design of Automotive Compressor for Integrated Portable Air Conditioning System
}

\author{
Muhammad Ikman Ishak $^{1,}{ }^{*}$, C.Y. Khor ${ }^{1}$, Mohd Riduan Jamalludin ${ }^{1}$, M.U. Rosli ${ }^{1}$, Suhaimi \\ Shahrin $^{1}$, Norsyahadah Yeop Wasir ${ }^{1}$, M.S. Zakaria ${ }^{1}$, A.F.M. Yamin ${ }^{2}$, Noor Diyana \\ Dahlan $^{1}$, and Wan Nur A'tiqah Wan Draman ${ }^{1}$ \\ ${ }^{1}$ Faculty of Engineering Technology, Universiti Malaysia Perlis, Level 1, Block S2, UniCITI Alam \\ Campus, Sungai Chuchuh, 02100 Padang Besar, Perlis, Malaysia \\ ${ }^{2}$ Faculty of Mechanical Engineering, Universiti Teknologi MARA, 13500 Permatang Pauh, Pulau \\ Pinang, Malaysia
}

\begin{abstract}
This study introduces a new concept of portable air conditioner which integrated with some available components in automotive air conditioning system. This new idea intends to solve the storage problems as well as to reduce the price of current portable air conditioner since some devices could directly be used from the automotive air conditioning system. The primary emphasis of this study was on the modification of automotive compressor design so as the system may alternately be operated. The length of conventional compressor shaft is extended to place an additional clutch pulley, a drive plate and a clutch coil. The new concept particularly the shaft and pulley were analysed through slope deflection and computational finite element analyses. The result of engineering analyses exhibited that the new design of compressor shaft and clutch pulleys promote a low risk of failure as the data values recorded are lower than the critical value for each criterion investigated.
\end{abstract}

\section{Introduction}

An air conditioning system is a system used to acquire cooling effect. Generally, the system is used to provide human comfort and some to fulfill the industrial needs. The effect of external and internal heat load will increase the indoor air temperature that subsequently increases the room temperature $[1,2]$. The mechanically-operated air conditioner may be classified into several groups such as individual room-typed, thermal storage, desiccantbased and many others including the portable-typed. Among the models of portable air conditioner that can be found are those of split system, single unit and evaporative cooler. The portable air conditioner is more demanding than the others as it provides minimal installation requirement, efficient energy consumption, economic space utilisation, ergonomic design and multi-functional system [3].

The use of portable air conditioner is not only limited for cooling a small room. It has also widely been used in outdoor travelling purposes. However, most portable air

* Corresponding author: ikman@unimap.edu.my 
conditioners are heavy and thus giving difficulty for the users to move them from one place to another. The number of components used in the system is directly associated with its weight and price. Thus, one of the best ways to produce a light-weighted portable air conditioner is by reducing the number of components used. This may possibly be achieved by integrating the existing portable air conditioner with the automotive air conditioning system.

To the best of author's knowledge, the idea of integrating between both systems has not been investigated yet. Therefore, the overall aim of this study was to design a portable air conditioner which integrated with some suitable components from the automotive air conditioning system. An emphasis is placed on the conceptual design and analysis of new compressor design.

\section{Design development}

The main principle of automotive air conditioning system is to remove heat from the passenger compartment to ambient air. It is similar with that of portable air conditioner which is used to provide cooling effect for a limited space size. The only differences between both systems are the latter utilising larger component size and higher cooling capacity. The automotive air conditioning system consists of several components such as compressor, condenser, evaporator, receiver drier, expansion valve, hoses, tubing and magnetic clutch [4]. The system is driven by car engine via belt and magnetic clutch. The magnetic clutch which comprises clutch coil is operated by $12 \mathrm{~V}$ direct current. At certain rotating speed, the clutch will engage the pulley to drive the compressor. The compressor will compress refrigerant from the evaporator through suction line to a higher pressure so that the heat from passenger compartment could be removed to the outside environment.

It is noteworthy that in designing the proposed system, some modifications on the related parts of automotive air conditioning system are required. Those important parts are the compressor shaft, compressor inlet and condenser outlet. The new system also demands several additional components namely an evaporator, two flexible refrigerant lines, an electric motor and an adapter.

\subsection{Compressor drive}

The preferred working principle of the proposed design is to operate both automotive and integrated portable air conditioning systems alternately without interfering to one another. In order to achieve that, the length of compressor shaft is extended so that an additional pulley, drive plate and clutch coil could be installed. Moreover, an electric motor installed with another extra pulley is rigidly attached to the car chassis to drive the extended shaft portion via V-belt, whilst the clutch coil is operated by an external adapter. These modifications will enable the automotive and integrated portable air conditioning system to be driven separately by the car engine and electric motor, respectively.

The extended shaft portion is designed as a stepped cylinder where the shaft shoulders are helpful in carrying any thrust loads and axially locating shaft elements such as pulley and bearing. The shaft is idealised to be made of cold-drawn steel (ANSI 1020 steel alloy) and has a length of $226 \mathrm{~mm}$ which is $20 \%$ longer than the standard one. Besides, the diameter of additional pulleys that are attached to the compressor and electric motor shafts are 112 and $125 \mathrm{~mm}$, respectively.

One may start to operate the integrated portable air conditioning system by turning on the electric motor and additional clutch coil adapter. The additional pulleys are then rotated and magnetic field will be generated. The clutch coil will pull the additional drive plate 
against the rotating pulley to drive the compressor. At the same time, the original drive plate will disengage and allow the compressor to be disconnected from the engine. If one wishes to turn on the automotive air conditioning system as before, they may reverse the process back to the original. Fig. 1 depicts the working principle of extended shaft portion elements in the proposed system.

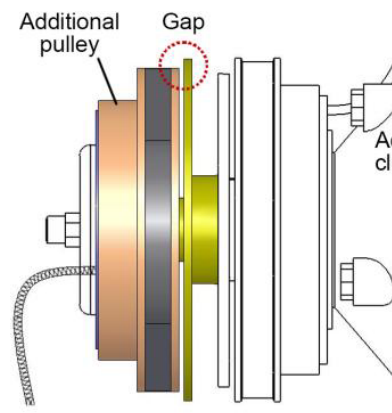

(a)

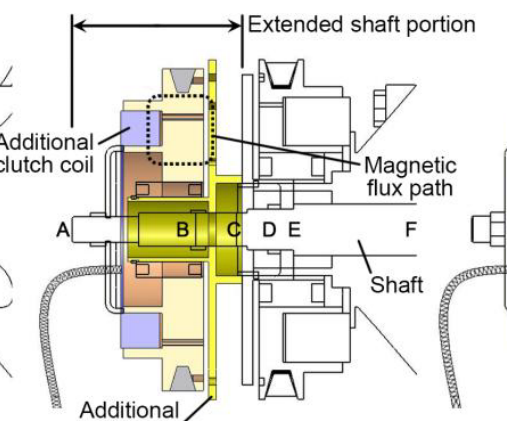

(b)

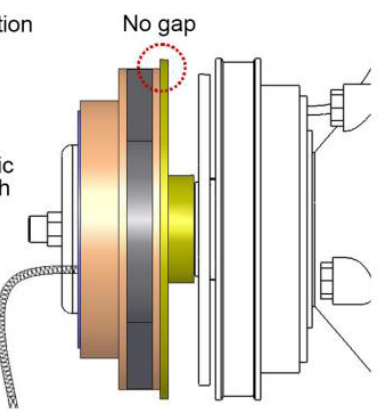

(c)

Fig. 1. The working principle of extended shaft portion elements. (a) There is a gap between the additional pulley and drive plate before the system starts. (b) As the electric motor and adapter are turned on, the additional clutch coil begins to generate magnetic field. (c) The rotating additional pulley pulls the additional drive plate to drive the compressor.

The magnitude of torque required to drive the compressor shaft by the electric motor is supposed to be equal or greater than that of car engine. It was thus determined that the cooling capacity of compressor is $6.04 \mathrm{~kW}$ for a space with the size of $29.5 \mathrm{~m}^{2}$. This had been calculated based on American Society of Heating, Refrigerating and Air Conditioning Engineers (ASHRAE) handbook [5]. From thermodynamic analysis, it was evident that the power needed to run the system is $1.22 \mathrm{~kW}$ and therefore giving the value of torque imposed on the compressor shaft driven by the car engine is $5.83 \mathrm{Nm}$.

\subsection{Ball valve}

As the two systems will be alternately operated, it is therefore vitally important to control the flow of refrigerant from the evaporator to condenser such that both systems could be well performed. There are two ball valves are employed to direct the refrigerant to flow in the suction and liquid line connecting to the condenser and evaporator, respectively. The ball valve contains a hole that allows the refrigerant to flow through whenever it is in line with the inlet and outlet of the suction or liquid line.

\subsection{Service port and schrader valve}

The system also requires another two valves installed at both ends of detachable refrigerant line where one end is connected to a port at the condenser outlet and the other at the compressor suction inlet. The fitting at each port is equipped with a Schrader-typed valve. The valve comes with a depressor and installed at the end of the refrigerant lines. As the refrigerant line is connected to the port, the depressor pushes inward the valve stem to open the valve. The valve and refrigerant line are designed to be automatically closed by pushing back the depressor against the port to prevent refrigerant loss. 


\section{Engineering analysis}

\subsection{Slope deflection analysis}

The slope deflection analysis was performed to find the maximum deflection of shaft body that probably generated while the shaft is operating. This is vitally important in shaft design as it may prevent excessive deflections which can eventually cause the edge-load bearings to failure. The method used in this analysis is Macaulay's or singularity function [6]. The analysis was conducted on the extended shaft body driven by the car engine and electric motor. The reaction forces imposed on the shaft due to ball bearing supports (at location B and E) for both drives were calculated from equilibrium force analysis. Fig. 2 illustrates all loadings applied on the shaft in free body diagram.

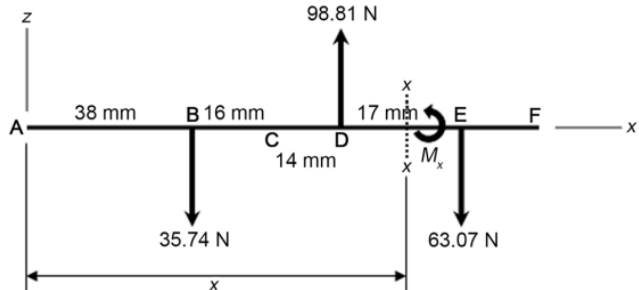

(a)

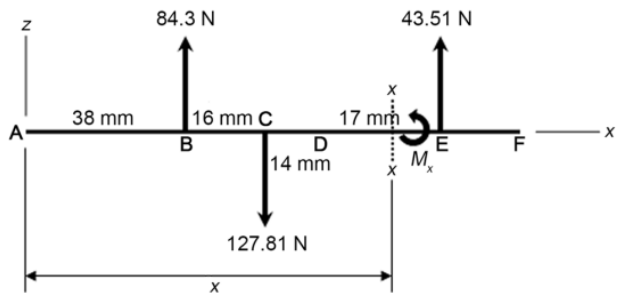

(b)

Fig. 2. The free body diagram of compressor shaft driven by (a) the car engine and (b) electric motor.

\subsection{Computational finite element analysis}

Another critical part of the proposed system which is the clutch pulley had been analysed via $3 \mathrm{D}$ finite element method. Both clutch pulleys driven by the car engine and electric motor together with the shaft body were designed using SolidWorks software. The clutch pulley and shaft were made of carbon steel and cold drawn steel alloy, respectively [7]. All materials were assumed to be isotropic, homogenous and linearly elastic [8-11]. For the car engine drive, a static torque of $5.83 \mathrm{Nm}$ was applied onto the groove surface of pulley in the clockwise direction. Different magnitude of torque $(8.18 \mathrm{Nm})$ was considered for the electric motor drive and applied at the same location. The contact surface between the clutch pulley and shaft was constrained in $x, y$ and $z$ directions to prevent any movement. The 3D models were then analysed using COSMOSXpress software to investigate the response of those parts towards the applied loading in terms of von Mises stress patterns.

\section{Results and discussion}

It was found in the slope deflection analysis that the electric motor drive $(-0.41 \mu \mathrm{m})$ predicted $29 \%$ greater maximum deflection magnitude of the shaft as compared to the car engine drive $(0.29 \mu \mathrm{m})$. Both drives seemed to share the same location where the maximum value was found which is towards the end of shaft body however occurred in different direction. The generated high value of deflection are likely to be due to a higher value of torque transferred from the electric motor $(8.18 \mathrm{Nm})$ to the shaft body than that of car engine $(5.83 \mathrm{Nm})$. Another possible clarification is that the additional clutch pulley connected to the electric motor has been installed and loaded slightly to the end of shaft body which leaving the shaft structure to be unevenly supported. This has resulted in a high bending moment generated at that particular area. 
In terms of equivalent von Mises stress results, the clutch pulley driven by the electric motor was observed to bear a greater stress value than that of car engine. This finding was in agreement with the results of deflection analysis on the shaft body where the car engine drive recorded more favourable outcomes. Fig. 3 exhibits the von Mises stress peaked at $1.48 \mathrm{MPa}$ in the electric motor drive and has no tendency to part failures since carbon steels are known can tolerate stresses up to $282.69 \mathrm{MPa}$ [7]. The generated stress values were also under the yield strength of material used thus suggesting that the clutch pulleys appear to provide adequate stability.

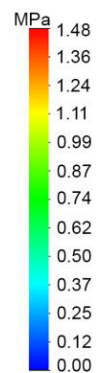

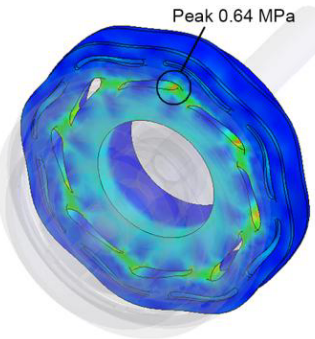

(a)

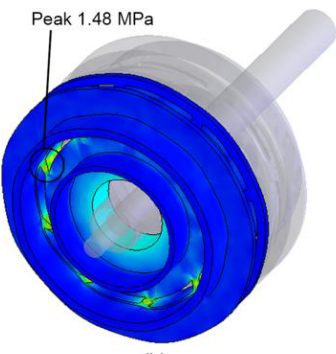

(b)

Fig. 3. Stress distribution within the clutch pulley driven by the (a) car engine and (b) electric motor.

\section{Conclusions}

The results of engineering analysis found that the extended compressor shaft satisfactorily sustains the bending moment loads in the slope deflection analysis for both drives. Both electric motor and car engine drives also provide adequate stability of the clutch pulleys in terms of mechanical stress outcomes obtained from the computational finite element analysis.

\section{References}

1. R. McDowall, Fundamentals of HVAC systems (Elsevier Science, 2007)

2. S. K. Wang, Handbook of air conditioning and refrigeration (McGraw-Hill Education, 2000)

3. Information on http://www.air-n-water.com

4. T. W. Birch, Automotive heating and air conditioning (Prentice Hall, 2005)

5. American Society of Heating, R. and A.-C. Engineers, ASHRAE handbook: HVAC systems and equipment (American Society of Heating, Refrigerating and AirConditioning Engineers, 2004)

6. F.P. Beer, E.R.J. Jr., J.T. DeWolf, Mechanics of materials (McGraw-Hill Education, 2005)

7. W.D. Callister, Materials science and engineering: an introduction (John Wiley \& Sons, Inc., 2002)

8. M.I. Ishak, M.R. Abdul Kadir, E. Sulaiman, N.H. Abu Kasim, Int. J. Oral Maxillofac. Implants, 28, 3 (2013)

9. M.I. Ishak, M.R. Abdul Kadir, E. Sulaiman, N.H. Abu Kasim, Int. J. Oral Maxillofac. Surg., 419 (2012)

10. M.I. Ishak, M.R. Abdul Kadir, E. Sulaiman, N.H. Abu Kasim, Biomedical Engineering and Sciences (IECBES) (2010)

11. A. Omar, M.I. Ishak, M.N. Harun, E. Sulaiman, N.H. Abu Kasim, Applied Mechanics and Materials, 121 (2012) 